\title{
Resumption of pituitary and ovarian activity post-partum: endocrine and ultrasonic observations in bromocriptine-treated women
}

\author{
Joke E.Haartsen', Maas Jan Heineman, \\ Margot Elings, Johannes L.H.Evers ${ }^{2}$ and \\ Ioana Lancranjan ${ }^{3}$
}

Department of Obstetrics and Gynaecology, De Wever Hospital, PO Box 4446, 6401 CX Heerlen, ${ }^{2}$ Department of Obstetrics and Gynaecology, Academisch Ziekenhuis Maastricht, The Netherlands and ${ }^{3}$ Department of Neuroendocrinology, Clinical Research, Sandoz Pharma Ltd, CH-4002 Basel, Switzerland

'To whom correspondence should be addressed

The resumption of pituitary and ovarian activity was investigated by hormonal measurements and ultrasound scanning in 45 healthy post-partum women who were treated with bromocriptine. Bromocriptine, $50 \mathrm{mg}$ (Parlodel LAR) was administered within $24 \mathrm{~h}$ post-partum. Plasma luteinizing hormone, follicle stimulating hormone, oestradiol, progesterone and prolactin concentrations were measured repeatedly and correlated with ultrasound measurements. Forty-one of the 45 women completed the study. A prompt fall in prolactin levels to normal (non-pregnant) values was observed within 24 h post-partum. Hereafter, a rapid return of the normal menstrual cycle was observed. Endocrine evidence of ovulation was obtained in 19/41 women within 1 month post-partum. Ultrasound measurements started at day 10 and were repeated regularly in 40 women. Ultrasound evidence of ovulation was found in $25 / 40$ women. Ultrasound findings appeared not to correspond with the hormonal measurements. It is conctuded that the resumption of pituitary and ovarian secretory functions post-partum is not always paralleled by a concomitant recovery of normal follicular growth and ovulation. Application of a progesterone threshold to judge resumption of ovulation post-partum should be reconsidered.

Key words: ovarian activity/post-partum/ultrasonic ovulation detection

\section{Introduction}

In Europe, for many years now, 2-bromo- $\alpha$-ergocriptine has been the single most important drug for the suppression of puerperal lactation. Bromocriptine has been shown to reduce increased puerperal prolactin levels to the normal non-pregnant range within 24-48 $\mathrm{h}$ after the beginning of treatment (Valsamis et al., 1987; Kremer et al., 1990a). It blocks the initiation of lactation and prevents breast engorgement and mastodynia. No rebound lactation occurs, particularly not when a depot form of bromocriptine is applied [Parlodel LA (long-acting) or Parlodel LAR (long-acting repeatable)] (Rolland et al., 1986; Kremer et al., $1990 \mathrm{~b})$. Bromocriptine allows a rapid return of pituitary activity post-partum. This is reflected in a rapid resumption of ovarian activity as judged by endocrine parameters. Hormonal signs of ovulation may occur as early as 21 days post-partum (Kremer et al., 1990a).

Several investigators have compared ultrasound findings with hormonal parameters in the normal menstrual cycle (Hackelöer et al., 1979; Wetzels et al., 1982; Bryce et al., 1982). The aim of the present investigation was to study, during puerperal suppression of lactation, the resumption of pituitary and ovarian function by means of ultrasound and hormonal parameters. This is the first study to combine hormonal and ultrasound measurements in post-partum research. We wanted to determine whether the rapid return of ovarian endocrine activity is accompanied by normal follicle development and ovulation, as judged by ultrasound.

Suppression of lactation was obtained by i.m. administration of $50 \mathrm{mg}$ Parlodel LAR. Parlodel LAR consists of microspheres of glucose-initiated poly D,L-lactide-coglycolide containing bromocriptine. The suspension of the microspheres in a vehicle containing carboxymethyl cellulose is made prior to the injection.

\section{Materials and methods}

\section{Patients}

Forty-five women participated in the study. The following inclusion criteria were selected. (i) No wish to breastfeed. (ii) Willingness to remain hospitalized for at least 1 day after the Parlodel LAR injection and to return to the hospital or be available at home for blood-sampling and ultrasound examinations on selected days thereafter. (iii) No relevant abnormal findings at the initial physical examination prior to drug administration, nor any abnormal laboratory value regarding vital functions.

No concomitant treatment that could influence the patients' metabolic or hormonal state was given during the observation period. Informed consent was given verbally in the presence of a third person. The protocol of the study was approved by the ethical committee of our hospital.

Seventeen women were primiparous, 28 were multiparous; mean age was 28 years (range $17-35$ years); mean height $166 \mathrm{~cm}$ (range 155-178 cm); mean weight $75 \mathrm{~kg}$ (range $57-109 \mathrm{~kg}$ ). All subjects had regular menstrual cycles prior to the present pregnancy. In seven women, the pregnancy was complicated by hypertension, three women received insulin therapy because of gestational diabetes and one woman had a 
placental abruption at 38 weeks. Forty-four women delivered at term, one woman delivered prematurely at 29 weeks. Three women delivered by Caesarean section.

\section{Intervention}

A deep intragluteal injection of bromocriptine, $50 \mathrm{mg}$ (Parlodel LAR) was administered within $24 \mathrm{~h}$ after delivery, at $0800 \mathrm{~h}$.

\section{Hormonal measurements}

To study the post-partum resumption of gonadotrophic function, blood samples were taken prior to the bromocriptine administration and 1, 2, 3, 4, 6, 12 and $24 \mathrm{~h}$ following the administration. Further blood samples were taken on days $2,4,7,10,14,17$, $21,28,42$ and 60 , at home, always between 0800 and $1000 \mathrm{~h}$. The serum was separated and frozen until assayed. All samples from each subject were measured in the same assay run. Prolactin, oestradiol-17- $\beta$, luteinizing hormone ( $\mathrm{LH})$ and follicle stimulating hormone (FSH) levels were measured.

Serum hormone concentrations were measured in duplicate. All between-assay coefficients of variations were $<8 \%$. Serum LH and FSH levels were determined by luminescence assay with Amerlite LH-30 and FSH-60 clone kits (Amersham, UK). The results are expressed in terms of International Reference Preparation (IRP) $68 / 40$ for LH and IRP 79/549 for FSH. The detection limit for LH was $0.12 \mathrm{U} / 1$ and for FSH $0.5 \mathrm{U} / 1$. Serum oestradiol and progesterone were measured by radioimmunoassay (Coat-a-count, Diagnostic Products, Los Angeles, CA). The detection limit for oestradiol was $0.03 \mathrm{nmol} / /$ and for progesterone $0.45 \mathrm{nmol} / \mathrm{l}$. Serum prolactin levels were determined by Pharmacia Delfia Prolactin assay with reference to IRP 84/500 and with a detection limit of $0.001 \mathrm{U} / \mathrm{l}$.

Progesterone levels were measured on days 14, 17, 21 and 28. At first, concentrations $\geq 6 \mathrm{nmol} / 1$ were used as indicators of an ovulatory cycle, as suggested by Kremer and co-workers (1990b). This threshold value was chosen to allow comparison with data in the literature. Cycles with a mid-luteal progesterone level $<9.6 \mathrm{nmol} / 1(3 \mathrm{ng} / \mathrm{ml})$ have been considered to reflect a lack of luteinization (Israel et al., 1972). In addition, in cycles with serum progesterone $<32 \mathrm{nmol} / \mathrm{l}$, Radwanska and Swyer (1974) found an incidence of ovulation disturbances as high as $50 \%$, but at levels $>32 \mathrm{nmol} / 1$, the incidence was only $4 \%$. For that reason, we regrouped our results in two other ways according to the highest progesterone value: $\geq 9.6 \mathrm{nmol} / \mathrm{l}$ and $\geq 32 \mathrm{nmol} / \mathrm{l}$.

\section{Ultrasound evaluation}

Follicular growth and ovulation were monitored by ultrasound at regular intervals. A real time scanner was used (Pie Medical Scanner 150, Maastricht, The Netherlands). Ultrasound examinations started on day 10 and were repeated on days 14, 17, 21, 24 and 28 or until ovulation had occurred. If an ovulation was expected between two measurements, scans were done more frequently until ovulation was established. All ultrasound measurements were performed at home. Due to the position of the ovaries 2 weeks post-partum, only abdominal scans were made. Ovulation was characterized by steady growth of a follicle, followed by complete disappearance of the sonolucent area or by a sharp reduction in its size.

As additional signs of ovulation, the appearance of free fluid in the pouch of Douglas and filling-in of the follicular content with echodense structures were used. In case a follicle did not rupture, ultrasound scans were continued until the largest follicle had reached a diameter of $30 \mathrm{~mm}$, or until the follicle did not grow any further for two successive measurements. All follicles were scanned in three perpendicular directions, and the mean diameter was calculated (Hamilton, 1986).

\section{Statistical analyses}

For statistical analyses Wilcoxon's test for non-parametric data was used. The pre-assigned significance level was $P<0.05$. The results are expressed as means \pm standard deviations.

\section{Results}

Forty-five women entered the study and 41 women completed it as scheduled. Following the Parlodel LAR injection, four women withdrew, each for personal reasons. After leaving the hospital, three women declined further blood sampling and ultrasound examinations. One woman was withdrawn due to technical problems with blood sampling.

\section{Prolactin}

As expected, all women had high plasma prolactin concentrations following delivery and prior to injection of Parlodel LAR $(3.22 \pm 1.70 \mathrm{U} / \mathrm{l})$. Within $12 \mathrm{~h}$ after the administration of Parlodel LAR, all women showed a rapid fall in plasma prolactin levels to $0.33 \pm 0.20 \mathrm{U} / 1$ (normal non-pregnant range $0.10-0.60 \mathrm{U} / \mathrm{l}$ ) (Figure 1). Seven women showed a minor increase of prolactin levels on day 10,17 or 21 with a maximum of $1.15 \mathrm{U} / \mathrm{l}$. Only two women showed slight signs of engorgement, without pain or milkflow. In three women with a minor increase of prolactin, ultrasound examination did reveal signs of ovulation.

\section{$\mathrm{LH}$ and FSH}

FSH and LH levels were below the level of detection ( $\mathrm{LH}<0.1$ $\mathrm{U} / \mathrm{l} ; \mathrm{FSH}<0.5 \mathrm{U} / \mathrm{l}$ ) for the first 2 days after delivery. FSH first

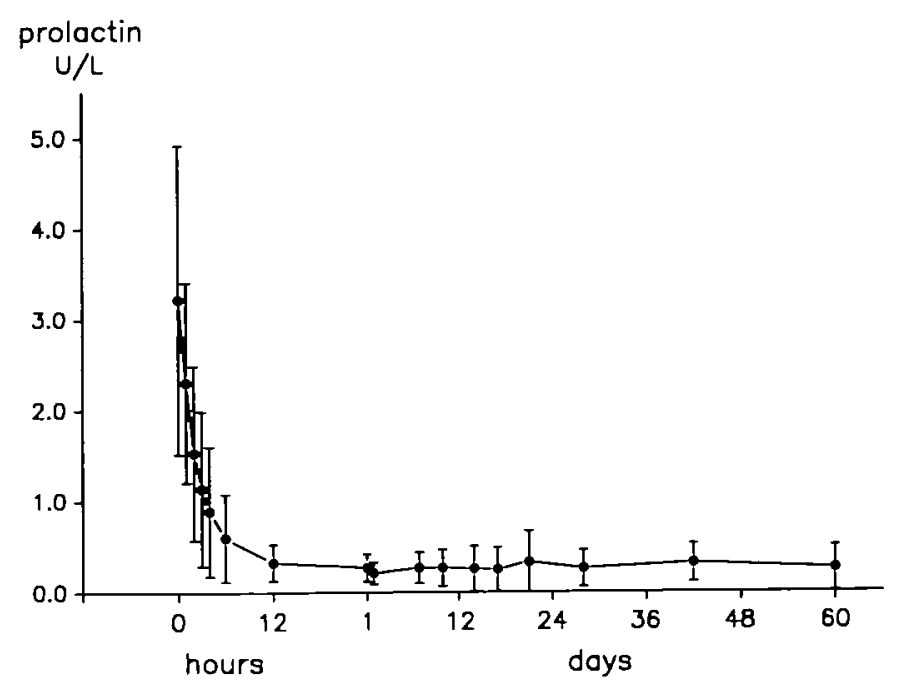

Fig. 1. Serum prolactin levels in 41 women after the administration of $50 \mathrm{mg}$ depot-bromocriptine on day 1 post-partum. 
became detectable by day 7 in 29 women. All women had a rise in FSH levels by day 10. Following the initial increase, maximum levels were observed on day $14(6.7 \pm 2.23 \mathrm{U} / \mathrm{l})$. Thereafter, the FSH levels declined slowly, comparable with a normal ovulatory cycle.

LH first became detectable on day 7 in 13 women and was detectable in 34 women by day 10 . LH started to rise later than FSH and increased more slowly. Maximum levels were reached on day 21 (6.73 $\pm 5.92 \mathrm{U} / \mathrm{l})$ (Figure 2).

\section{Oestradiol-17 $\beta$}

Within 7 days, all women reached early pre-ovulatory oestradiol levels (normal range: early follicular phase $0.2-1.5 \mathrm{nmol} / \mathrm{l}$ during ovulation $1.3-2.2 \mathrm{nmol} / 1$, luteal phase $0.7-1.5 \mathrm{nmol} / \mathrm{l}$ ). A nadir was seen on day $10(0.45 \pm 0.19 \mathrm{nmol} / \mathrm{l})$ followed by

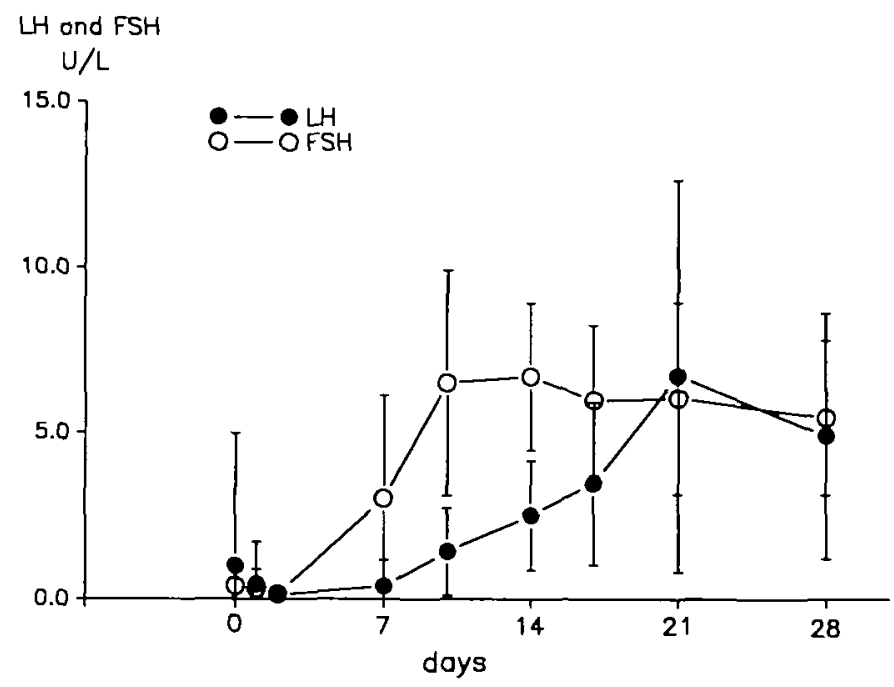

Fig. 2. Serum luteinizing hormone ( $\mathrm{LH})$ and follicle stimulating hormone (FSH) levels in 41 post-partum women after the administration of $50 \mathrm{mg}$ depot-bromocriptine on day 1 post-partum.

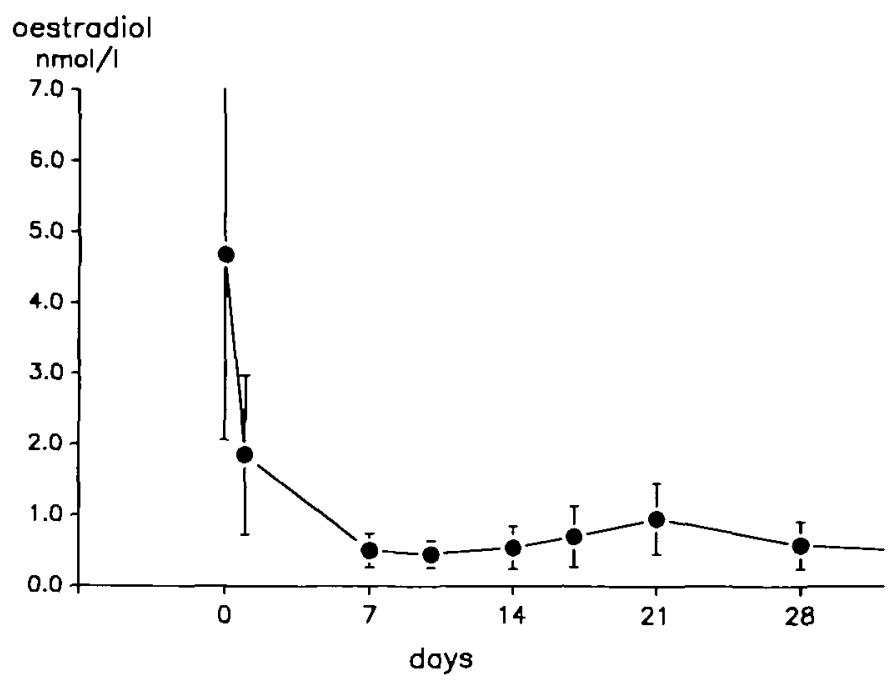

Fig. 3. Serum oestradiol levels in 41 post-partum women after the administration of $50 \mathrm{mg}$ depot-bromocriptine on day 1 post-partum. a significant increase with a maximum on day 21 of $0.95 \pm 0.50$ nmol/1 (Figure 3).

\section{Progesterone}

High levels of progesterone were measured at the time of the administration of Parlodel LAR: $63.0 \pm 46.6 \mathrm{nmol} / 1$ (normal range early follicular phase $0.3-2.0 \mathrm{nmol} / \mathrm{l}$ ). Early follicular levels were measured in all women on days 14,17 and 21 . Increased levels were obtained on day 28 . In 19 women, a progesterone level $\geq 6 \mathrm{nmol} / \mathrm{l}$ was obtained, 16 women had a level $>9.6 \mathrm{nmol} / \mathrm{l}$ and only four women would have had an ovulatory cycle had $32 \mathrm{nmol} / \mathrm{l}$ been used as the threshold for ovulation. The mean levels of progesterone on day 28 were $11.3 \mathrm{nmol} / 1$ (range $0.1-67.4 \mathrm{nmol} / \mathrm{l}$ ) (Figure 4).

\section{Ultrasound evaluation}

Valid ultrasound measurements were obtained in 40 of the 41 patients. In 35\%, transonic areas indicating follicle growth were seen at the first scan on day 10. Ultrasound findings appeared not to correspond with the hormonal findings.

In Table I different threshold levels of progestrone are shown, as related to the ultrasound findings. If a threshold of $6 \mathrm{nmol} / \mathrm{l}$ was used as an indication of an ovulatory cycle, 19 women would have had an ovulation. In 12 of these women, ultrasound

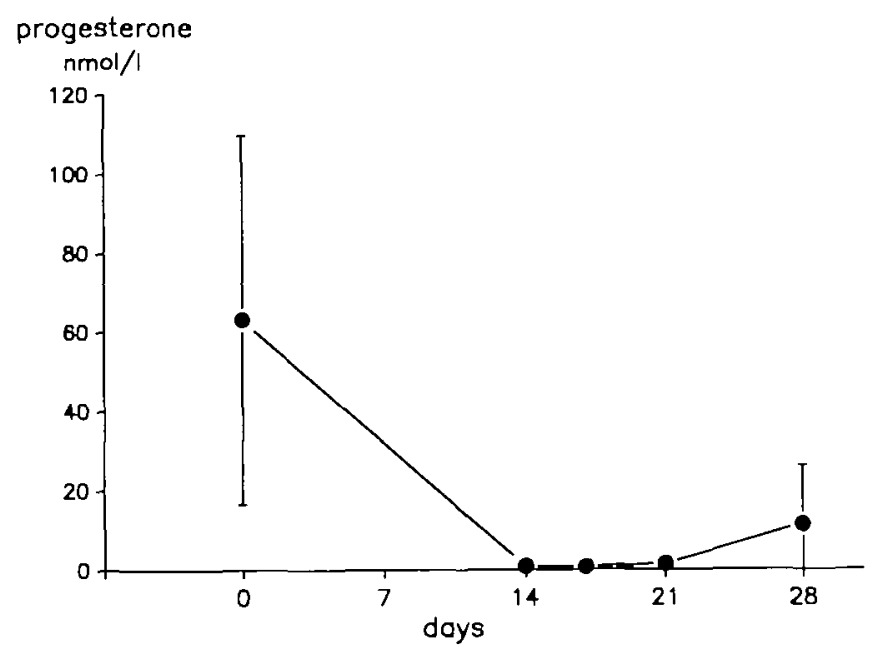

Fig. 4. Serum progesterone levels of 41 post-partum women after the administration of $50 \mathrm{mg}$ depot-bromocriptine on day 1 postpartum.

Table I. Hormonal measurements compared with ultrasound findings in post-partum non-lactating women treated with bromocriptıne

\begin{tabular}{llc}
\hline $\begin{array}{l}\text { Progesterone } \\
\text { threshold } \\
\text { (nmol/l) }\end{array}$ & Ultrasound (no. of patuents) \\
\cline { 2 - 3 } & Ovulation & No ovulation \\
\hline$<6$ & 13 & 9 \\
$\geq 6$ & 12 & 6 \\
$<9.6$ & 14 & 11 \\
$\geq 9.6$ & 11 & 4 \\
$<32$ & 21 & 15 \\
$\geq 32$ & 4 & 0 \\
\hline
\end{tabular}


measurements corresponded with the hormonal parameters. In five women the ultrasound scans were inconclusive: follicle growth was seen without evidence of ovulation, and the follicle disappeared slowly or became cystic without evidence of rupure. In one woman, no follicle growth could be observed, and in one woman no scans were made. In 22 women, progesterone levels $<6 \mathrm{nmol} / \mathrm{l}$ were obtained. Surprisingly, 13 of these 22 women had evidence of ovulation on ultrasound scanning. In six women, only follicle growth but no ovulation was observed and three women showed no follicle growth at all. If the threshold was raised to 9.6 or $32 \mathrm{nmol} / \mathrm{l}$, an increasing difference between ultrasound and hormonal measurements would have been observed. Sixteen women had progesterone levels $>9.6 \mathrm{nmol} / \mathrm{l}$, only four women had levels $>32 \mathrm{nmol} / 1$. Of the 16 women with a progesterone $\geq 9.6 \mathrm{nmol} / \mathrm{l}$, only 11 showed ovulation on ultrasound scanning. In one woman, ultrasound revealed no follicle growth at all. Progesterone levels in her case reached a maximum of $10.9 \mathrm{nmol} / \mathrm{l}$. Twenty-five women had a progesterone level $<9.6 \mathrm{nmol} / \mathrm{l}$ on day 28 . In this group, 14 women had ultrasound signs of ovulation, in nine women only follicle growth could be observed without an ovulation and two had no follicle growth at all.

In all women with a progesterone $\geq 32 \mathrm{nmol} / \mathrm{l}$, ovulation was affirmed by ultrasound. In the 37 women who had progesterone levels $<32 \mathrm{nmol} / \mathrm{l} 21$ had an ovulation on ultrasound. Thirteen women showed follicle growth only and only two had no follicle growth at all (in one woman, no ultrasound measurements were made). If ovulation was seen on ultrasound examination, it always occurred between day 17 and day 28 .

Using the ultrasound examinations as a reference, the hormonal data were rearranged. In 25 of the 40 women an ovulation was diagnosed by ultrasound. In this group, 12 women had progesterone $\leq 6 \mathrm{nmol} / \mathrm{l}, 13$ women $\geq 6 \mathrm{nmol} / 1$, 11 women $\geq 9.6 \mathrm{nmol} / 1$ and only four women had progesterone levels $\geq 32 \mathrm{nmol} / 1$.

In all women with no evidence of follicle growth on ultrasound examination, the ovaries were easy to identify. In the 37 women who showed evidence of follicle growth or ovulation on ultrasound scanning, 32 had a concomitant rise in oestradiol. In all women with at least a doubling of oestradiol, ultrasound confirmed ovulation.

\section{Discussion}

The resumption of gonadotrophic function in post-partum nonlactating women treated with bromocriptine (Parlodel LAR) in our study is in accordance with results from the literature. A prompt fall in prolactin to normal non-pregnant levels was seen within $24 \mathrm{~h}$ post-partum. This initiated a return of the normal menstrual cycle starting with the rise of FSH levels between day 7 and day 10 , followed by an increase in LH levels. Progesterone levels suggesting ovulation ( $\geq 6 \mathrm{nmol} / \mathrm{l}$ ) were observed in 19 women on day 28 . This threshold value was used to allow comparison with data in the literature. In our opinion, this threshold is however too low to ascertain that ovulation has taken place. For that reason, we used three different threshold levels: progesterone $\geq 6 \mathrm{nmol} / \mathrm{l}, \geq 9.6 \mathrm{nmol} / \mathrm{l}$ and $\geq 32 \mathrm{nmol} / \mathrm{l}$. Although serum progesterone samples were only taken on day
21 and 28 in the first month post-partum, we strongly believe that these findings are conclusive with regard to luteal activity, because they were highly correlated with an oestradiol rise in the follicular phase. All women with a rise of oestradiol in the follicular phase showed a rise in progesterone levels at day 28 and no significant changes in oestradiol levels occurred in women with low progesterone levels at day 28 .

Our data indicate that, based on hormonal findings, a quick return of pituitary and ovarian function would be expected, with an ovulation in almost $50 \%$ of the women within 4 weeks postpartum. Ultrasound measurements in our study, however, revealed that in the first month post-partum, many subtle disturbances occur in follicle growth and ovulation. Therefore, hormonal parameters suggesting ovulation do not always reflect a complete return to normal prepregnant ovarian function.

Accuracy in comparison with ultrasound findings was $47.5 \%$ if a progesterone threshold of $6 \mathrm{nmol} / 1$ was applied, $57.5 \%$ at $9.6 \mathrm{nmol} / 1$ and $47.5 \%$ at $32 \mathrm{nmol} / 1$. The increased occurrence of anovulatory cycles and defective luteal phases in the puerperium and following a spontaneous abortion has been described before (Gray et al., 1987; Donnet et al., 1990). The return to normal in the subsequent cycles suggests a gradual recovery of hypothalamic or pituitary function after childbirth.

In the early puerperium, the reproductive axis remains dormant, presumably in part because of pituitary refractoriness to gonadotrophin releasing hormone $(\mathrm{GnRH})$ stimulation, in part because of ovarian refractoriness to gonadotrophin stimulation (Vemer, 1979). In the course of the first few spontaneous menstrual cycles, normal ovarian ovulation activity is gradually restored.

The present study draws attention to the dissociation between the endocrine activity of pituitary and ovary and functional ovarian activity, i.e. follicle growth and ovulation. The biological activity of a given glycopeptide hormone is not always accurately reflected in even the most highly specific radioimmunological assay. Moreover, gonadotrophins are secreted in multiple heterogeneous forms. The specific biological activity of FSH isohormones may influence follicular development post-partum profoundly without the overall immunoactivity being a suitable indicator. Deglycosylated glycoproteins have, for example, been shown to be competitors of the intact hormone in receptor binding, but these isohormones have decreased potencies to stimulate steroidogenesis (Calvo et al., 1986). The ratio between bioactive and immunoactive FSH varies throughout the menstrual cycle and throughout reproductive life (Jia et al., 1986). It is tempting to speculate that the lack of association between ovarian secretory and ovulatory activity in the early post-partum period reflects in part the dissociation between the several active components of the reproductive system, which our routine laboratory immunoassays were unable to pick up.

The importance of differential stimulation of the ovary by the two most important pituitary glycoprotein hormones has recently been demonstrated by Mannaerts and co-workers (1991). They showed, in rats, that administration of pure (recombinant) FSH induced antral follicle growth, but no steroidogenesis. After the combined administration of FSH and LH the plasma oestradiol levels increased in an FSH dose-dependent manner. The differential increase of puerperal FSH and LH levels found in 
the present study might be responsible for the dissociation between steroidogenesis and folliculogenesis in the first menstrual cycle post-partum.

In conclusion, our findings demonstrate that even if hormonal changes suggest ovulation, the first spontaneous cycle after delivery is often characterized by disturbances of follicle growth and follicle rupture. Further research in this area is needed to find explanations for this difference between the hormonal and ultrasonic findings.

\section{Acknowledgements}

We thank Mr A.H.J.Gijzen, Mr H.H.P.Janssen and their colleagues for performing the assays and Renske Thoren for her assistance in collecting the data. This work was supported by a research grant from Sandoz Ltd, Basel, Switzerland.

\section{References}

Bryce,R.L., Shuter,B., Sinosich,M.J., Stiel,J.N., Picker,R.H. and Saunders,D.M. (1982) The value of ultrasound, gonadotropin, and estradiol measurements for precise ovulation prediction. Fertil. Steril., $37,42-45$.

Calvo,F.O., Keutmann,H.T., Bergert,E.R. and Ryan,R.J. (1986) Deglycosylated human follitropin: characterization and effects on adenosine, $3^{\prime}, 5^{\prime}$-phosphate production in porcine granulosa cells. Biochemistry, 25, 3938-3943.

Donnet,M.L., Howie,P.W., Marnie,M., Cooper,W. and Lewis,M. (1990) Return of ovarian function following spontaneous abortion. Clin. Endocrind., 33, 13-20.

Gray,R.H., Campbell,O.M., Zacur,H.A., Labbok,M.H. and MacRae,S.L. (1987) Post partum retum of ovarian activity in nonbreastfeeding women monitored by urinary assays. J. Clin. Endocrinol. Metab., 64, 645-650.

Hackelöer,B.J., Fleming,R., Robinson,H.P., Adam,A.H. and Coutts,J.R.T. (1979) Correlation of ultrasonic and endocrinologic assessment of human follicular development. Am. J. Obstet. Gynecol., $135,122-126$.

Hamilton,C.J.C.M. (1986) The role of ultrasound in the fertility clinic. Thesis, University of Limburg, Maastricht.

Israel,R., Mishell,D.R., Stone,C., Thorneycroft,I.H. and Moyer,D.L. (1972) Single luteal phase serum progesterone assay as an indicator of ovulation. Am. J. Obstet. Gynecol., 122, 1043-1046.

Jia,X.C., Kessel,B., Yen,S.S.C., Tucker,E.M. and Hsueh,A.J.W. (1986) Serum bioactive follicle-stimulating hormone during the human menstrual cycle and in hyper- and hypogonadotropic states; application of a sensitive granulosa cell aromatase bioassay. J. Clin. Endocrinol. Metab., 62, 1243-1249.

Kremer,J.A.M., Rolland,R., van der Heijden,P.F.M., Schellekens,L.A., Vosmar,M.B.J.G. and Langranjan,I. (1990a) Lactation inhibition by a single injection of a new depot bromocriptine. Br. J. Obstet. Gynaecol., 97, 527-532.

Kremer,J.A.M., Rolland,R., van der Heijden,P.F.M., Thomas,C.M.D. and Langranjan,I. (1990b) Retum of gonadotropic function in postpartum women during bromocriptine treatment. Fertil. Steril, 51, 622-627.

Mannaerts,B., De Leeuw,R., Van Ravenstein,A. and Kloosterboer,H. (1991) Biological properties of recombinant human follicle stimulating hormone. Hum. Reprod., Abstract Supplement 7th Annual Meeting ESHRE, p. 4.

Radwanska,E. and Swyer,G.I.M. (1974) Plasma progesterone estimation in infertile women and in women under treatment with clomiphene and chorionic gonadotropin. J. Obstet. Gynaecol. Br. Commonw., 81, $107-112$.
Rolland,R., Nijdam,W., Weyer,A. and Langranjan,I. (1986) Prevention of puerperal lactation with Parlodel Long-Acting (Parlodel LA). Eur. J. Obstet. Gynecol. Reprod. Biol., 22, 337-343.

Valsamis,J., Chavez,H., Westelinck,K., Haemers,M., Frances,G. and L'Hermite,M. (1987) Inhibition of puerperal lactation by means of a single injection of bromocriptine retard. Eur. J. Obstet. Gynecol. Reprod. Biol., 25, 43-51.

Vemer,H.M. (1979) Lactatıonal amenorthoea. Thesis, Nijmegen.

Wetzels,L.C. and Hoogland,H.J. (1982) Relation between ultrasonographic evidence of ovulation and hormonal parameters: luteinizing hormone surge and initial progesterone rise. Fertil. Steril., 37, $336-341$

Received on January 21, 1992; accepted on April 4, 1992 